\title{
Parental Knowledge, Attitudes and Practices in Early Childhood Development among Low Income Urban Parents
}

\author{
Taslima Begum ${ }^{1,2}$ \\ ${ }^{1}$ MPH Program, American International University-Bangladesh (AIUB), Bangladesh \\ ${ }^{2}$ BRAC Institute of Educational Development, BRAC University, Bangladesh
}

Received June 21, 2019; Revised August 23, 2019; Accepted September 23, 2019

Copyright $\odot 2019$ by authors, all rights reserved. Authors agree that this article remains permanently open access under the terms of the Creative Commons Attribution License 4.0 International License

\begin{abstract}
The aim of the study was to examine parents' current level of knowledge, attitudes and practices related to early childhood development (ECD). The findings found that few parents have good knowledge and practices regarding ECD although most of them have good level of attitude. These results indicate gaps among knowledge attitude and practices. Regarding child's health and nutrition about $55 \%$ of infants were exclusively breastfed. Moreover, $45 \%$ infants received complementary liquids foods (typically around 4-5 months) and $12 \%$ were given infant formula. Interestingly, mothers engaged both controlling and indulgent feeding behaviors toward their child. Moreover, most of the mother used negative disciplinary techniques to guide their children. Finding on parental support for early learning found that $54 \%$ of households engaged in early and school readiness activities with their child. Only 25\%, 3 to 5 year's old children attended kindergarten school among them $92 \%$ children recognized letter or numbers. Only $8 \%$ parents perceived their child had some type of physical or learning difficulty despite most of them (94\%) did not consult with others. However, $18 \%$ children had been seriously injured when parents leaving their child to someone else.
\end{abstract}

Keywords Early Stimulation, Feeding Practices, School Readiness, Child Discipline, Child Protection

\section{Introduction}

Early Childhood Development (ECD) 'the key to a full and productive life'[1], is a powerful investment for socially and economically in the future. Investing in early years, it is not only beneficially for children and their families, but also to societies and the entire global community, because they help mitigate the impact of adverse early experiences. If children are not treated well at early years lead to poor health (e.g., non-communicable diseases such as obesity, cardiovascular disease, and diabetes), poor educational attainment, economic dependency, increased violence and crime, greater substance abuse and depression - all of which add to the cost and burden in society [2]. However, 250 million or $43 \%$ of children in Low- and middle-income countries (LMIC) are unable to realize their full development potential in 2016 (WHO) [3]. Hence, this was predicted to create a 20 per cent loss of adult productivity during the later stages of life [4]. What was concerning is that 25 per cent of children in LMIC like Bangladesh were exposed to psycho-social risk factors such as poor stimulation, lack of learning opportunities, parent unresponsiveness, and parental inability to understand infant behavior [5]. Each of these risk factors has been linked to caregiving practices and can be prevented using simple public health initiatives like responsive parenting programs that promote health, nutrition and early learning, which affects children's overall development [6].

Studies have shown that integrated intervention, specifically parenting and family support program can improve cognitive development and school readiness through providing knowledge about ECD, the importance of early stimulation, proper caregiving practices and ensuring the quality of the home environment. Since parents' knowledge, prevailing attitudes and quality practice or engagement played a positive role in children's healthy development [7].

Therefore, a better understanding of the parents' knowledge, attitudes and practices would benefit researcher, public health and ECD professional and policy makers. The understanding of the level of knowledge, 
attitude and practice might help us to formulate integrated intervention to promote ECD by increasing parents' knowledge, attitudes and practice related to ECD. It also helps investor, government, and policy makers to list down priorities for investment, provide evidence-based interventions, and improve the effectiveness of specific policies and programs that provide optimal conditions for success.

However, many children younger than 5 years in developing countries, like Bangladesh are exposed to multiple risks, including poverty, malnutrition, poor health, and un-stimulating home environments, which detrimentally affect their cognitive, motor, and social-emotional development[4]. In this situation, it is vital to examine parental knowledge, attitude, and practices before designing any intervention program. A research cited slum people follow less optimal parenting styles, including harsher parenting [8]. Similarly parents from Kenya, a low income country lack parenting skills[9]. Moreover poor parents spend less time reading to their children, less time talking with them, and less time visiting museums and libraries with them[10, 11, 12] and poor children are also exposed to fewer cognitively stimulating activities in the home[13]. Although many studies examine parental knowledge, attitude, and practices related to ECD, little evidence found in the Bangladeshi context. In addition, it is not clear about the current situation of parental knowledge, attitude, and practices related to ECD. As a result, the present study interested to study parental knowledge, attitude, and practices related to ECD.

The overall purpose of the research is to assess the level of knowledge, the prevailing attitudes and current practices of parents related to ECD and school readiness. Particularity the study has the following specific objectives: to assess parent's current existing knowledge related to ECD, to assess parent's prevailing attitude regarding ECD, to identify a gap among knowledge, attitude and practices, to identify the extent and quantity of early learning activities (early stimulation) in the home and parental behaviors related to infant feeding, nutrition, and child protection, to identify underlying socio-demographic factor related to level of knowledge, attitude and practices. The hypothesis of the study was existing knowledge, attitudes and practice related to ECD are poor among parents. Moreover, there is a gap between knowledge and attitude and, attitude and practice.

\section{Method}

\subsection{Study Design}

The study followed cross sectional design, in which data were collected through face to face parents' interview with pre tested structured questionnaire.

\subsection{Study Locale and Population}

The data collection was carried out from Korial slum, the largest slum area in Dhaka, Bangladesh. The slum is located at the heart of the Dhaka North City Corporation, adjacent to the busting biasness area of Gulshan that hold residential zones for the wealthy part of the population and is home to most of the foreign embassy. The perceived land area of the Korial varies between 95 acres (about $4 \mathrm{~km}^{2}$ ) and 200 acres (about $8 \mathrm{Km}^{2}$ ) and the home to more than 200,000 people [14]. The majority of this slum living under the poverty line and working in extremely low income jobs[15]. The target groups of the study were under 5 years' old children's parents.

\subsection{Sample}

In the present study data were collected from 107 parents who have children under 5 years from Korial slum. Participants were selected using multi-stage sampling (purposive and convenience sampling).

\subsection{Research Instrument}

In the present study, pre tasted structured questionnaire was used to collected data. The content validity of the instrument was maintained by developing the instrument on the basis of UNICEF KAP (Knowledge, Attitude and Practice) Questionnaire and literature review regarding ECD. In addition to that, opinion from ECD experts \& researchers were considered. The reliability of the instrument was established by pre-testing the instrument among 15 population. After that necessary modification was made on the basis of pretest and then the final questionnaire (data collection tools) was developed.

The tool was constructed in Bangla language which includes knowledge, attitude and practices regarding ECD. In addition to that, some socio-demographic information e.g., respondent's age, sex, socioeconomic status, educational qualification, occupation etc. were also collected from parents. In the knowledge part, all items were open ended. However in order to achieve standardization in responses and an efficient data collection process, most items were close ended in the practices and attitude part. Most items in practices section designed to elicit concrete and objective responses (i.e., yes/no; when the child stopped breastfeeding). The items were asked in simple language to limit the risk of bias during translation to the local languages. In designing the questionnaire, personal or sensitive questions were carefully avoided.

Two versions of the KAP questionnaire were used in this study. One version was used for parents of children aged 6 months to 2 years (infants and toddlers) which related to infant and young child feeding practices and another version was used for parents of children aged 3 to 5 years (kindergarten aged children) which related to 
children's school readiness skills, transition to school and participation in kindergarten. The questionnaire mainly focused on three issues (health and nutrition, family support for early learning, and child protection) related to ECD and school readiness. The items in each of the three themes are outlined below:

Health and Nutrition. It includes ten items from WHO Indicators of infant and young children feeding practices and six items from UNICEF Multiple Indicator Cluster Survey Disability and disability module. These items measure infant and young child feeding practices.

Family support for learning. Items of this part measure children's school readiness skills, enrollment and transition to primary school and parents' perception about kindergarten.

Child protection. This theme includes five items, issues related to protection such as adequate care, injuries and disciplinary practices.

\subsection{Procedure}

Data were collected individually from each respondent through face to face interview. At first rapport were built through practicing greetings to inform participants about the purpose of the research. Then verbal consent was taken from parents. Moreover, parents were informed of the study procedures, risks and benefits, protection of the privacy, and parents' freedom to discontinue participation. One field Researcher Assistant engaged in data collection, crosschecking, and data entry. Each filled questionnaires were re-checked just after completing the interview so that inconsistence responses could be corrected. Data collection was continued until the desired number of sample was met.

\subsection{Data Management and Analysis Plan}

After collection of data, all interviewed questionnaires were checked and cleaned manually. Then, all incomplete or missing data were discarded as incomplete data. Raw data were checked twice and coded in the same day of data collection.

Data were entered and analyzed through SPSS version 20 (Statistical Package for Social Science). For the test of significance, Chi-square and Multiple liner regression analysis were used to find out the relationship between factors and to find the dependency status between dependent and independent variables.

\subsection{Limitation of the Research}

This research was conducted by a cross-sectional study and the causality could not be ensured. It is the most important limitation of this research. As the outcome is based on "respondents-report" of the respondents, results are vulnerable to social desirability and recall biases.

\section{Findings}

The results of the present study are illustrated below, showing parental knowledge, attitude and practices related to ECD.

\subsection{Socio Demographic Characteristics of Respondent}

Among 107 participants 104 participants were mother and remaining 3 were father. Participants' age were ranging between 18 to 40 years old, with an average of 25 years old. Among the participants, $47 \%$ were illiterate and the remaining $53 \%$ were literate. Most of the participants (48\%) did not pass any class, $22 \%$ completed their primary education, $23 \%$ completed secondary education and only $7 \%$ completed SSC or equivalent level.

Most of the participant were not employed or homemaker (79\%), only $21 \%$ were employed. Among the employed participants most were day labor (64\%) followed by garment's worker (14\%), 9\% were service holder, $9 \%$ did handicraft, and only $4 \%$ were doing micro business.

However, most participants lived in nuclear family. About $84 \%$ participant lived at nuclear family where $16 \%$ lived in joint family. Family members ranged from 3 to 12 persons with an average of 4.5 persons. $36 \%$ family, most of the family consisted with 3 persons followed by 4 persons $(31 \%)$, and then 5 persons (17\%). Only $1 \%$ families had 12 members.

Around 50\% family's monthly family income was 6000 to 10000 taka. On the other hand, only $3 \%$ participant's monthly family income was less than 5000 taka and $47 \%$ participants' monthly family income was more than 10000 taka. However, 98\% participants had no land. Interestingly, only $7 \%$ participants always faced scarcity of money, and 19\% sometimes faced scarcity of money. On the other hand, $42 \%$ families' maintained income and expenditure balance and $32 \%$ families can made savings.

\subsection{Parental Knowledge Attitude and Practice}

The section presents the parents' current level of knowledge, attitude, and practices. To determine the of parent's knowledge, attitude and practices the total score was categorized as no, low, moderate and good. The total raw score (separately for knowledge, attitude, and practices) of 0 were considered as no, 1 to $40 \%$ of total score was categorized as low, 41 to $80 \%$ were considered as moderate and above $80 \%$ were considered as good knowledge, attitude or practices (Table 1). 
Table 1. Categorization of parents' knowledge, attitude and practices level

\begin{tabular}{|l|l|l|l|}
\hline Instrument & Item no & Total score & Score \\
\hline Knowledge & 10 & 28 & $\begin{array}{l}\text { No knowledge: } 0 \\
\text { Low knowledge: 1-11 } \\
\text { Moderate Knowledge: } 12-22 \\
\text { Good knowledge: 23-28 }\end{array}$ \\
\hline Attitude & 10 & 10 & $\begin{array}{l}\text { No attitude: } 0 \\
\text { Low attitude: } 1-4 \\
\text { Moderate attitude: } 5-8 \\
\text { Good attitude: } 9-10\end{array}$ \\
\hline Early Learning practices & 5 & 5 & $\begin{array}{l}\text { No practices: } 0 \\
\text { Low practices: } 1-2 \\
\text { Moderate practices: 3-4 } \\
\text { Good practices: } 4-5\end{array}$ \\
\hline Responsive feeding practices & 8 & $\begin{array}{l}\text { No practices: 0 } \\
\text { Low practices-6 } \\
\text { Moderate practices: } 7-13 \\
\text { Good practices: } 14-16\end{array}$ \\
\hline
\end{tabular}

Table 2. Distribution of parents' KAP level (\%)

\begin{tabular}{|c|c|c|c|c|c|c|c|c|}
\hline \multirow{2}{*}{ variable } & \multicolumn{4}{|c|}{ 0-2 years $(\mathbf{n}=56)$} & \multicolumn{5}{c|}{ 3-5 years $(\mathbf{n}=\mathbf{5 1})$} \\
\cline { 2 - 11 } & \multicolumn{4}{|c|}{ KAP level } & \multicolumn{5}{c|}{ KAP level } \\
\cline { 2 - 11 } & No & Low & Moderate & Good & No & Low & Moderate & Good \\
\hline Knowledge about ECD & 0 & 72.7 & 27.3 & 0 & 0 & 71.2 & 28.8 & 0 \\
\hline Attitude on child rearing practices & 0 & 0 & 9.1 & 90.9 & 0 & 0 & 3.8 & 96.20 \\
\hline Early learning practice & 9.1 & 29.1 & 30.9 & 30.9 & 11.5 & 42.3 & 19.2 & 26.9 \\
\hline Responsive feeding practices & 0 & 2.8 & 44.9 & 4.7 & & \multicolumn{2}{c}{$\mathrm{ns}$} \\
\hline
\end{tabular}

Table 2 represents that there were not any parents having no knowledge or good knowledge. Most of the parents had lower level of ECD knowledge (about 73 and 71 percentages for parents having 0-2 years and 3-5 years old child respectively). In contrast above $90 \%$ parents had good attitude (about $91 \%$ for parents having children under 2 years and $96 \%$ parents $3-5$ years old child respectively). However, parents did not practice early stimulation/early learning practices (ELP) as much as with older children with compared to the younger one. About 31\% parents' did good and moderate level of practices and $30 \%$ parents did lower level of practices with their younger children. On the other hand, $42.3 \%$ parents having 3-5 years old child did the lower level of practices. However, about $45 \%$ parents practiced responsive feeding $(\mathrm{RF})$ practices with their child.

To determine the association among parents' knowledge, attitude and practice we conducted chi-square test (Table 3 and Table 4). Table 3 reveals that there is no association between early learning practices with knowledge. Similarly, early learning practices had not any significant association with parental attitude. Consistently parent's responsive feeding practices had not any significant association with knowledge and prevailing attitude (Table 4). From these two tables, we can conclude that there may gaps among parental Knowledge, attitude and practices.

Correlation of socio demographic factor with parental KAP. Partial correlation was conducted to see the association of all possible socio demographic variables with parental knowledge, attitude, and practices. Table 5 presented that monthly father's literacy; family income, income and expenditure balance, and asset index were positively correlated with the parent's knowledge. However, monthly family income was negatively correlated with the parent's attitude. The table also represented that literate mother and mothers having higher educational qualification practiced more early learning stimulation. However, employed mother practiced less early learning stimulation with their child. On the other hand, father's educational qualification, income \& expenditure balance, crowding index, and toilet facilities at home were positively correlated with parent's responsive feeding practices (RF). 
Table 3. Association of Early learning practices with knowledge and attitude

\begin{tabular}{|c|c|c|c|c|c|c|c|c|c|}
\hline \multirow{2}{*}{\multicolumn{2}{|c|}{ Variable }} & \multicolumn{5}{|c|}{ level of Early Learning Practice $(n=107)$} & \multirow{2}{*}{ Chi-square } & \multirow{2}{*}{ df } & \multirow{2}{*}{$p$ value } \\
\hline & & No & Low & Moderate & Good & Total & & & \\
\hline \multirow{2}{*}{ Knowledge } & Low & $81.8 \%$ & $76.3 \%$ & $59.3 \%$ & $74.2 \%$ & $72.0 \%$ & \multirow{2}{*}{3.13} & \multirow{2}{*}{3} & \multirow{2}{*}{.37} \\
\hline & Moderate & $18.2 \%$ & $23.7 \%$ & $40.7 \%$ & $25.8 \%$ & $28.0 \%$ & & & \\
\hline \multirow{2}{*}{ Attitude } & Moderate & $18.2 \%$ & $7.9 \%$ & $7.4 \%$ & $0.0 \%$ & $6.5 \%$ & \multirow{2}{*}{4.75} & \multirow{2}{*}{3} & \multirow{2}{*}{.19} \\
\hline & Good & $81.8 \%$ & $92.1 \%$ & $92.6 \%$ & $100.0 \%$ & $93.5 \%$ & & & \\
\hline
\end{tabular}

Table 4. Association of responsive feeding practices with knowledge and attitude

\begin{tabular}{|c|c|c|c|c|c|c|c|c|c|}
\hline \multirow{2}{*}{\multicolumn{2}{|c|}{ Variable }} & \multicolumn{5}{|c|}{ level of Responsive feeding $(n=55)$} & \multirow{2}{*}{ Chi-square } & \multirow{2}{*}{ df } & \multirow{2}{*}{$p$ value } \\
\hline & & No & Low & Moderate & Good & Total & & & \\
\hline \multirow{2}{*}{ Knowledge } & Low & $0 \%$ & $0 \%$ & $75.0 \%$ & $40.0 \%$ & $73.2 \%$ & \multirow{2}{*}{3.99} & \multirow{2}{*}{2} & \multirow{2}{*}{.13} \\
\hline & Moderate & $0 \%$ & $0 \%$ & $25.0 \%$ & $60.0 \%$ & $26.8 \%$ & & & \\
\hline \multirow{2}{*}{ Attitude } & Moderate & $0 \%$ & $0 \%$ & $10.4 \%$ & $0.0 \%$ & $8.9 \%$ & \multirow{2}{*}{.92} & \multirow{2}{*}{2} & \multirow{2}{*}{.63} \\
\hline & Good & $0 \%$ & $0 \%$ & $89.6 \%$ & $100.0 \%$ & $91.1 \%$ & & & \\
\hline
\end{tabular}

Table 5. Correlation of knowledge, practices, and attitude with socio-demographic factors

\begin{tabular}{|c|c|c|c|c|}
\hline Variables & Knowledge & Attitude & ELP & $\mathbf{R F}$ \\
\hline Child' s Sex ( 1 is coded as boy and 2 as girl) & -.084 & -.008 & .044 & .084 \\
\hline age & -.004 & -.073 & -.063 & .130 \\
\hline Mothers age & .122 & -.105 & -.144 & -.017 \\
\hline Mother's literacy & .131 & -.029 & $.202^{*}$ & .262 \\
\hline Mother's educational level & .147 & -.025 & $.249^{* *}$ & .221 \\
\hline Mother is employment status & -.042 & .028 & $-.416^{* *}$ & -.062 \\
\hline Father's age & .081 & -.084 & -.181 & -.001 \\
\hline Father's literate & $.199^{*}$ & .154 & .189 & .161 \\
\hline Father's education qualification & -.030 & -.011 & -.130 & $.270^{*}$ \\
\hline type of family ( 1 is coded as nuclear family and 2 as joint family) & -.105 & -.117 & -.068 & -.068 \\
\hline monthly family income & $.211^{*}$ & $-.223^{*}$ & .010 & .074 \\
\hline income and expenditure balance & $.262^{* *}$ & -.027 & .188 & $.370^{* *}$ \\
\hline Asset index & $.254^{* *}$ & -.092 & .102 & .157 \\
\hline Crowding index & .095 & -.027 & .026 & $.329^{*}$ \\
\hline Toilet facility at house & .027 & -.111 & .062 & $.286^{*}$ \\
\hline
\end{tabular}

${ }^{*} P<0.05,{ }^{* *} P<0.01$

(Note. ELP: Early Learning Practices, RF: Responsive feeding)

Table 6. Correlation among knowledge, practices, and attitude

\begin{tabular}{|c|c|c|c|c|}
\hline \multirow{2}{*}{ Variable } & Knowledge & Attitude & $\mathbf{E L P}$ & $\mathbf{R F}$ \\
\cline { 2 - 5 } & $\mathbf{( N = 1 0 7 )}$ & $\mathbf{( N = 1 0 7 )}$ & $\mathbf{( N = 1 0 7 )}$ & $\mathbf{( N = 5 6 )}$ \\
\hline Knowledge & 1 & --- & --- & --- \\
\hline Attitude & .045 & 1 & --- & --- \\
\hline ELP & .131 & .161 & 1 & --- \\
\hline RF & $.284^{*}$ & -.001 & .200 & 1 \\
\hline
\end{tabular}

${ }^{*} p<0.05$

Correlation between parental knowledge, attitude, and practice. Partial correlation was conducted to see the association parental knowledge, attitude, and practices. Table 6 represents that parental knowledge significantly and positively correlated with responsive feeding practices.
However, parental knowledge not significantly correlated with early learning practices and attitude. On the other hand, parents' attitudes not significantly correlated with parents' early learning practices and responsive feeding practices.

Furthermore, to observe the causal relationship between two variables and the contribution of predictor variables on the criterion variable we conducted multiple regressions (Table 9). Table 7 has shown that knowledge about ECD can explain $8 \%$ of the variance in Responsive feeding practices. However, socio-demographic factors (asset index, crowding index, the mother was employed or not, mother's literacy, income and expenditure balance, monthly family income, mother's educational level) can explain 25 percentage of variance on RF practices. On the 
other hand, socio-demographic factors (asset index, crowding index, the mother is employed or not, mother's literacy, income and expenditure balance, monthly family income, mother's educational level) can explain 23 percentage of variance on ELP (Table 7).

Finally, in a separate analysis we conducted another multiple liner regression (Table 8) to see the effect of knowledge (predictor variable) on practices related to ECD with controlling all potential confounders. Table 8 represents that variance explained by knowledge on RF increase $25 \%$ to $27 \%$. Nevertheless, $R$ Square change (2\%) was not significant. Similarly, variance explained by knowledge on ELP increase from $23 \%$ to $24 \%$. But $R$ Square change (2\%) was not significant.

Table 7. Regression model for KAP and socio-demographic factor

\begin{tabular}{|c|c|c|c|c|c|c|c|c|c|}
\hline $\begin{array}{c}\text { Criterion } \\
\text { variable }\end{array}$ & \multicolumn{1}{|c|}{ Predictors } & R & R square & $\begin{array}{c}\text { Adjusted R } \\
\text { square }\end{array}$ & SS & df & MS & F & $p$ \\
\hline RF & \multicolumn{1}{|c|}{ Knowledge } & .28 & .08 & .064 & 9.647 & 1 & 9.647 & .741 & .03 \\
\hline Knowledge & $\begin{array}{l}\text { Asset index, crowding index, Mother is } \\
\text { employed or not, mother's literacy, income } \\
\text { and expenditure balance, monthly family } \\
\text { income, mother's educational level }\end{array}$ & .33 & .11 & .48 & 7.773 & 7 & .253 & .759 & .10 \\
\hline ELP & $\begin{array}{l}\text { Asset index, crowding index, Mother is } \\
\text { employed or not, mother's literacy, income } \\
\text { and expenditure balance, monthly family } \\
\text { income, mother's educational level }\end{array}$ & & .23 & .18 & 1.132 & 7 & .733 & .270 & .00 \\
\hline RF & $\begin{array}{l}\text { Asset index, crowding index, Mother is } \\
\text { employed or not, mother's literacy, income } \\
\text { and expenditure balance, monthly family } \\
\text { income, mother's educational level }\end{array}$ & & .50 & .14 & 0.677 & 7 & .668 & .277 & .04 \\
\hline
\end{tabular}

Table 8. Regression model of parental knowledge in the adjusted model

\begin{tabular}{|c|c|c|c|c|c|c|c|}
\hline \multirow[b]{2}{*}{ Dependent variable } & \multirow[b]{2}{*}{ Model } & \multirow[b]{2}{*}{$\mathbf{R}$} & \multirow{2}{*}{$\begin{array}{c}\mathbf{R} \\
\text { Square }\end{array}$} & \multirow{2}{*}{$\begin{array}{c}\text { Adjusted R } \\
\text { Square }\end{array}$} & \multicolumn{3}{|c|}{ Change Statistics } \\
\hline & & & & & $\begin{array}{c}\text { R Square } \\
\text { Change }\end{array}$ & F Change & Sig Change \\
\hline \multirow{2}{*}{$\mathrm{RF}$} & 1 & .499 & .249 & .140 & .249 & 2.277 & .044 \\
\hline & 2 & .522 & .272 & .148 & .023 & 1.483 & .229 \\
\hline \multirow{2}{*}{ ELP } & 1 & .483 & .234 & .179 & .234 & 4.270 & .000 \\
\hline & 2 & .490 & .240 & .178 & .007 & .855 & .357 \\
\hline
\end{tabular}

Model 1 income and expenditure balance, mother's literacy, Mother's employment status, crowding index, monthly family income, asset index, and mother's educational level

Model 2 income and expenditure balance, mother's literacy, Mother's employment status, crowding index, monthly family income, asset index, and mother's educational level, mother's knowledge

Table 9. Percentage of parents involved in both responsive and controlling feeding behaviors

\begin{tabular}{|l|l|c|}
\hline Types of parent child interaction during feeding & $84 \%$ \\
\hline \multirow{4}{*}{ Responsive } & parents talk to the child and encourage him or her during meal & $80 \%$ \\
\cline { 2 - 3 } & Parents sit with child during feeding & $79 \%$ \\
\cline { 2 - 3 } & Parents wash hand with soap and water before feeding & $75 \%$ \\
\cline { 2 - 3 } Controlling/ indulgent & The child let parents know when he/she is full & $98 \%$ \\
\hline & Parent allows the child to eat sweets to keep him/her happy & $75 \%$ \\
\cline { 2 - 3 } & Parents have to control child while eating, such as his or her body or head & $35 \%$ \\
\cline { 2 - 3 } & Parents try to get the child to finish all of his/her food during meal & $30 \%$ \\
\cline { 2 - 3 } & Parents force the child to eat & \\
\hline
\end{tabular}




\subsection{Findings on Health and Nutrition}

This sectionpresents parents' knowledge and practices about health and nutrition such as the source of information these parents used on infant and child feeding practices, initiation of breastfeeding, exclusive breastfeeding, complementary feeding practices; responsive feeding practices and child disability

\subsection{Sources of Information on Infant Feeding}

The study found that experiences from previous child's feeding practices (about 50\%) and mother/ mother in law (27\%) were the two most important source of information for mothers to makedecisionsaboutfeeding their infantor young child. Interestingly, $11 \%$ mother said that husband helped them to make decisions about infant and child feeding practices. However, only 9\% mothers received information on infant or young children's feeding from a health clinic, or community health worker. No motherreported havingreceivedinfant feeding information fromaparenting program.

Early initiation of breast feeding. The study found $98 \%$ mothers initiated breastfeeding in the first hour after birth. The few cases where mothers did not breastfeed were due to medical reasons.

Exclusive breastfeeding for six months. The study found that $55 \%$ of infants were exclusively breastfed and $45 \%$ of infants received complementary liquids prior to 6 months of age (typicallyaround 4-5 months). However, $12 \%$ of infants were given infant formula primarily for medical reasons.

Introducing complementary solid foods. Most of the mother $(89 \%)$ introduced complementary solid foods at 6 months. only $7 \%$ mothers started at age 7 months and others' introduced solid food to infants between 6 and 12 months of age (Figure 1). Among the solid foods, Hopscotch was the single most common first solid food, with $48 \%$ of infants receiving this as one of their first foods. Other common first solid foods included rice (28\%), Semia/ Payes: kind of vermicelli (14\%) and semolina (4\%). Some infants also received biscuits, eggs or fish as first foods.

Responsive Feeding Practices. Responsive feeding (RF) refers to a reciprocal relationship between an infant or child and his or her caregiver that is characterized by the child communicating feelings of hunger and satiety through verbal or nonverbal cues, followed by an immediate response from the caregiver. It includes caregiver responsiveness and a belief in infant/toddlers' ability to self-regulation. Hence, infants' and young children should be feed with patients and slowly. In addition to that, young children should be encouraged to eat, but not forced to eat.

The study found that most of the parents' use both responsive and controlling behavior during feeding their child (Table 9). Most mothers reported that they engaged in responsive feeding behaviors including sitting with their child during meals and talking to their child during meals. At the same time, mothers also reported engaging in controlling and indulgent feeding behaviors including physically controlling their child while eating and allowing them to eat sweet to keep him/ her happy. Mothers reported that they started to give their child small finger foods between the ages of 3 and 18 months and, on average, at 10 months of age.

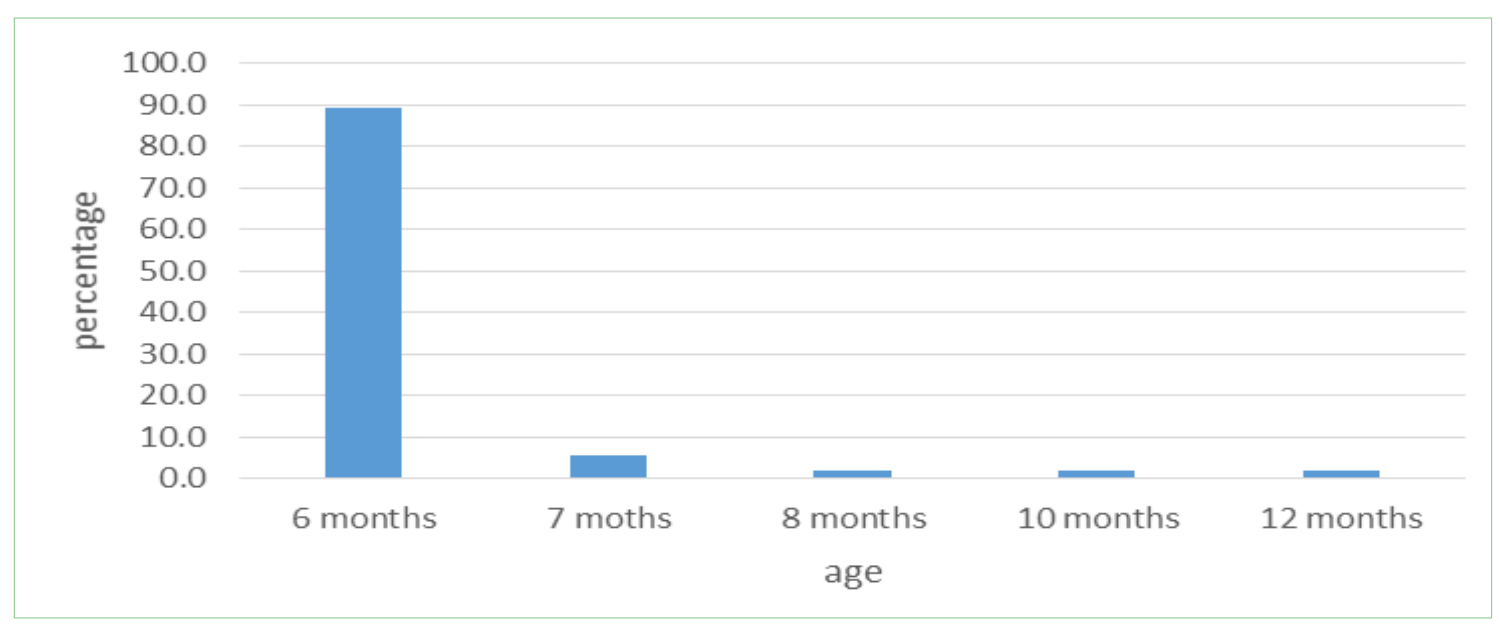

Figure 1. Introduction of complementary solid food by age 
Child disability. The study found that $8 \%$ of parents perceived that their child had some type of physical or learning difficulty. Themost commondisability concerns amongst parents of kindergarten-aged children were walkingdifficultiesfollowed byspeaking or seeing (Table 10). Interestingly, parents had infant or toddler did not perceive that their child had any types of physical or learning difficulties, suggesting that earlier physicalor learning difficulties maynotbe identified.

Table 10. Parental reports of child disability, diagnosed andundiagnosed $(N=107)$

\begin{tabular}{|c|c|c|c|}
\hline \multicolumn{4}{|c|}{ Reports of child disabilityby type } \\
\hline & Aged 2-3 & Aged 3.5 & Total \\
\hline Seeing & $0 \%$ & $2 \%$ & $2 \%$ \\
\hline Hearing & $0 \%$ & $0 \%$ & $0 \%$ \\
\hline Speaking & $0 \%$ & $2 \%$ & $2 \%$ \\
\hline Walking & $0 \%$ & $4 \%$ & $4 \%$ \\
\hline
\end{tabular}

In terms of health seekingbehaviors, $94 \%$ of mothers reported that they did not speak to anyone about their concern related to perceived child disability. Other mothers reported thattheyeitherspoke with the local nurse, family members or doctor regarding theirconcerns.

\subsection{Findings on Parental Support for Early Learning}

Children's development was facilitated by the active involvement of parents in learning activities. Parents foster cognitive development by reading or looking at picture books, telling stories or spending time naming, counting and drawing with their child. Parents foster socio emotional development by playing with children, singing them songs or taking them out of the home.

The study measured parental support for early cognitive and socio-emotional development, which was facilitated by the active involvement of parents in learning by reading books, showing picture books, singing song, play with children, taking child outside the home, counting or drawing. This chapter presents findings on the following issues:

Parental support for learning. In most of the household (54\%) at least one parent/caregiver engaged in three or more early and school readiness activities with their child in the past three days. The five possible activities included: reading or looking at picture books, storytelling, playing, singing, and counting or drawing. Parents on average, engaged in 2.6 early learning activities with their children.

Story telling. Story telling was the least common practices among early learning activities: at least one parents engaged in story telling with their child in $41 \%$ households in past three days. However, both parents engaged in story telling with their child in $1 \%$ households in past three day. Moreover, neither parents nor any other family members engaged in story telling with their child in $36 \%$ households in past three days.

Reading book with children. Reading book or showing picture book with children was most common and early learning and school readiness activities that parents engaged in with their child (Fig 2). At least one parent reads or looked at picture books with their child in $77 \%$ of households during the past three days. However, both parents read with their child in $1 \%$ of households. Around $55 \%$ mothers, $18 \%$ father and $11 \%$ sibling older than 15 years old read with their child. Parents reported that they read the following types of book or reading materials to their child:

- Children's' books including picture books, text books, religious book (79\%)

- $\quad$ Magazine or newspaper $(2 \%)$

- Poster or wall calendar (1\%)

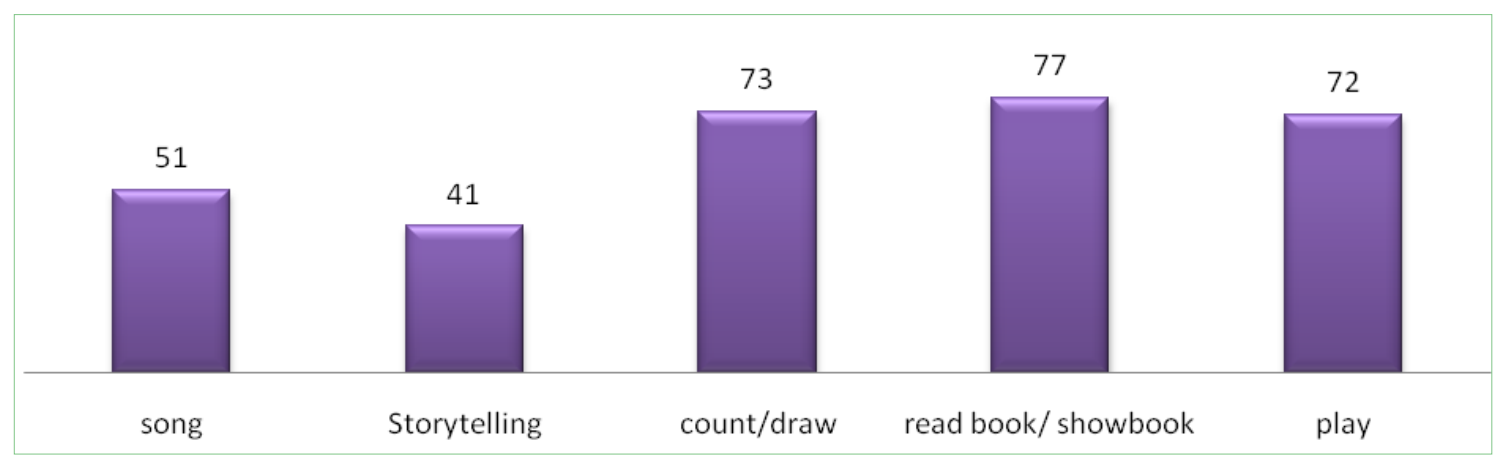

Figure 2. Percentage of households in which at least one parent engage in activities to promote early learning and school readiness in the past three days 
Neither parent reads or looked at picture books in the past three days in $23 \%$ households. Parents in households where parents or any other family members did not read with their child reported that the main reasons were that they were too busy to read (45\%), the child was too young to read $(20 \%)$, they did not have access to books $(15 \%)$, parents could not read (15\%), and other reasons (5\%).

Counting or drawing with children. At least one parent counted or drew with their child in $73 \%$ of households during the past three days (and both parents counted or drew with their child in $1 \%$ of household). Neither parents nor any other family member counted or drew with their child in $19 \%$ of households. This was one of the most common early learning and school readiness activity that parents engaged in with their child.

Playing with children. At least one parent played with their child in $72 \%$ of households during the past three days (and both parents played with their child in 3\% of household). The study found that children generally played with store brought toys and household objects:

- Toys from a store or market (37\%)

- Household objects such as bowls, cups, pots (26\%)

- Homemade toys (9\%)

- $\quad$ Things for writing and drawing $(6 \%)$

- Outside objects such as sticks and rocks $(1 \%)$

- Things that Make or play music (1\%)

Neither parents nor any other family member played with their child in $16 \%$ of households. Parents reported that the main reason they did not play with their child because they were too busy to play with $(80 \%)$, and they did not have access to play materials (13\%). A few mother reported that they did not think it was important to play.

Singing song. Singing song with their child is one of the less common early learning activities that parents engaged with. Parents sang the following types of songs with their child:

- Popular songs or songs they heard on the radio $(70 \%)$

- $\quad$ Religious songs (14\%)

- Songs that help children to learn such as counting or naming colors $(6 \%)$

Is child's gender or age associated with parental support for learning? Child's gender was not significantly correlated with parental engagement in early learningactivitiesin the home (Table 5). Thissuggests that parents of girls engaged in a similar number of early learning activities as parents of boy.

Children's age was not significantly correlated with the number of early activitiesthat parents engaged in with their child. Thissuggests that parents engaged in similar early learning activities with infants and toddlers and with kindergarten aged children. However, mothers were much more likely to play with infants/toddlers than with kindergarten agedchildren. On the other hand, mothers were more likely to count or draw with their kindergarten aged children than with toddler and infant (Fig 3).

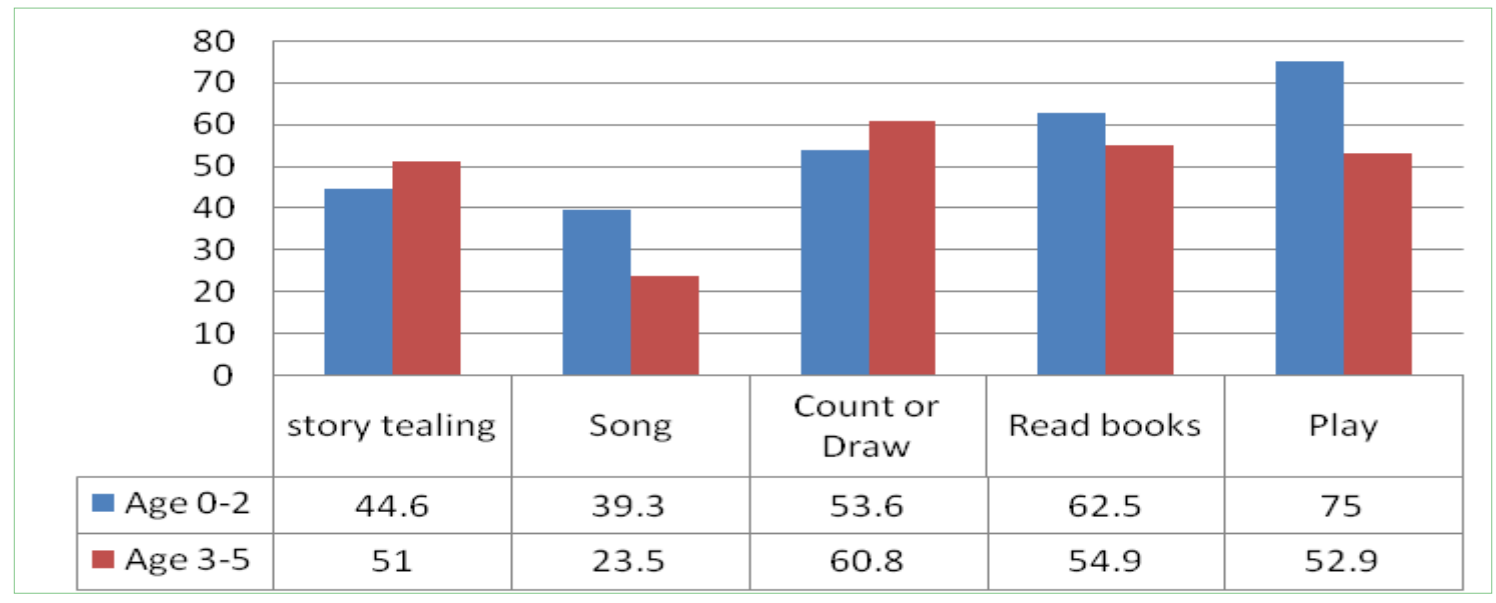

Figure 3. Percentage of mother that engaging different types of early learning activities by child's age 
Kindergarten participation. The study found that around $25 \% 3$ to 5 year's old children attended kindergarten school. The most common reason that a child did not attend kindergarten was that they were perceived the kindergarten was too expensive $(47 \%)$, or it would not benefit the child $(33 \%)$. Other reasons included: the child is too young $(10 \%)$ or that the kindergarten was too far from home $(8 \%)$. The study found that only $10 \%$ of parents had met with the kindergarten teacher to discuss their child's learning. Children who participated in kindergarten had significantly higher scores on the assessment of school readiness milestones. However, mothers were not as positive about the benefits of kindergarten: $50 \%$ mothers reported that their child had learned 'a little' from kindergarten and 33\% reported that their child did not learn much at all, while only $12 \%$ of mothers reported that their child had learned 'a lot'.

Children's school readiness. A measure of children's school readiness was developed for this study that included five key early learning milestones: letter recognition, reading, number recognition, independence, fine motor ability andgetting along with other children. Parentsprovided estimates on whether or not their child wasable to complete these tasks. The results show that children's scores on school readiness milestones were significantly correlated with child's age $(r=.48, p<.01$, $\mathrm{n}=51)$ but not with child's gender $(r=-.408, p=\mathrm{ns}$, $\mathrm{n}=51)$. Scores were also significantly and positively associated with the numberofhousehold assets $(r=.36$, $p<.01, \mathrm{n}=51)$, and with maternal level of education $(r=.39, p<.01, \mathrm{n}=51)$. Scores were not significantly associated with participation in kindergarten. However, parents reported that among the kindergarten group $92 \%$ children recognized letter or number whether it was $50 \%$ for non-kindergarten children.

Nearly all parents reported that their child got along well with other children, could follow simple instruction and their child was able to do things independently. Many also reported that the child was not distracted easily. The lowest score was related to early reading: only $26 \%$ of children in kindergarten and $15 \%$ of children not in kindergarten were able to read four simple and popular words $51 \%$ of parents also reported that their child hits, kicks or bitesother childrenand/or adults.

Transition to primary school. The study finds that parents planned to send their child to Grade 1 starting at different ages,rangingfrom between 4 and 7 years old. Most of the parents, $65 \%$ parents, had the plan to send their child to primary school at age 5 . Interestingly, $23 \%$ parents did not yet make any plan to send their child to primary school.

Only $45 \%$ of parents reported that they look for information on how to prepare their child for school. Family and friends were the most common source of information for parents on how to prepare children for school (33\%) followed by teachers (12\%). Only $1 \%$ parents reported that they received information from a parenting program on preparing children for school.

\subsection{Findings on Child Protection}

Teaching children self-control and acceptable behavior is an integral part of child development. Positive parentingpracticesteachchildren how to handle emotions or conflicts in a manner that preserves children's self-esteem andsafety. This section presents the findings on child protection, child injuries, and parental disciplinary practices.

Leaving children in inadequate care. The study found that $18 \%$ of mothershad regular activities outside the home that involvedleavingtheir child in the care of someone else typically a grandmother or father and sometimes aunt. On average mothers 1.26 hours mothers had regular activities outside the home that involvedleavingtheir child in the care of someone else. The study found that $56 \%$ (on average 2.16 days per week) of children were sometimes left alone for more than an hour. Furthermore, 58\% (on average 2.12 days per week) of children were occasionallyleft in the care of another child (lessthan 10 years old) formore than an hour.

Child injuries. The study finds that $18 \%$ of children had been seriously injured. Parents reported that injuries were related to wounds $(16 \%)$, accidents $(2 \%)$, or burn $(1 \%)$.

Child discipline. Parents reported that when their child did something wrong, the most common discipline strategy they used was to shout, yell or scream (34\%) and explain why something is $(30 \%)$ wrong. Therefore, parents approached child discipline with both negative and positive verbal strategies. In addition to that $12 \%$ parents reported that they used physical punishment (shake, spank, slap or pull ear, pinch) as disciplinary strategy. However, $12 \%$ mother did nothing, when their childrendid something wrong.

Figure 4 reveals that percentage $(29 \%$ and $39 \%$ respectively) of mothers who reported using verbal aggression was high even amongst infant and toddlers. 


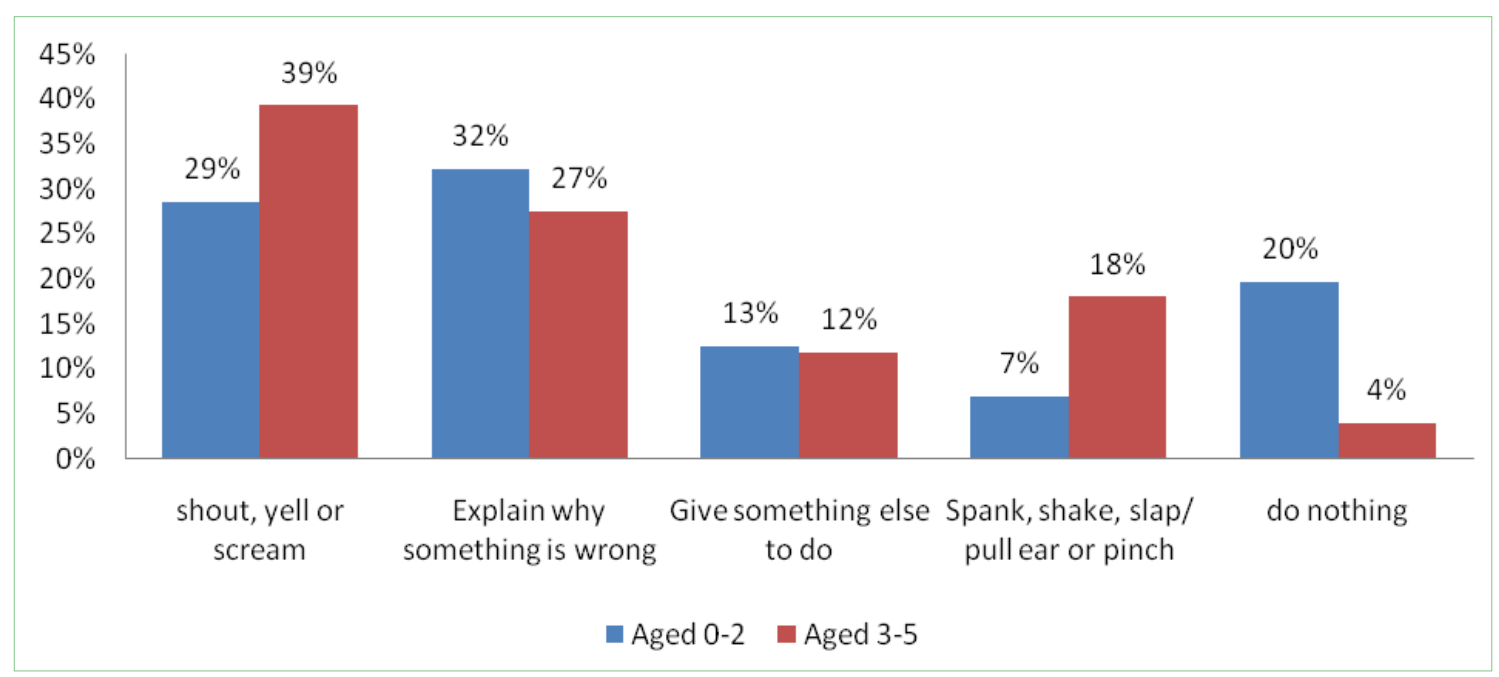

Figure 4. Percentage of children who experienced violent, verbal or positive discipline by age group

\section{Discussion}

The aim of this study was to assess the level of knowledge, prevailing attitudes and current practices of parents and to investigate whether there is a gap between knowledge, attitude, and practices related to ECD and school readiness. The study investigates key issues that influence children's health, learning, psychosocial functioning in the first five years of life. Specially, the study investigates optimal breastfeeding and complementary feeding practices, family support and opportunities for early learning in the home environment, and issues related to child protection including exposure to violent discipline and children left in inadequate care. Reviewing the relevant literature in detailed, it was hypothesized that, existing knowledge and attitude and practice related to ECD are poor among parents and there might be a gap between knowledge and attitude and practice.

The findings of the study partially supported the hypotheses. Results presented in Table 2 indicates knowledge and practices (both early learning and responsive feeding) were lower among parents. Comparing parents between low and high socio-economic status, the research found that parents in higher socio-economic group had greater knowledge about child development [16]. On the other hand parents' lower lever of knowledge reflected on parents' poor practice regarding child care. These findings were also similar to previous findings $[10,11,12]$. However, present study found that the prevailing attitude toward ECD is good among parents. And, table 3 and 4 revels that there was a gap between knowledge and attitude, and practices and attitude. These results indicate parents' feel importance of stimulation, nutrient food and other factors that accelerate child development but they had not specific information why these factors are important and how these factors affect development.
Regression model (Table 7) indicates that some socio-demographic factor (e.g., asset index, crowding index, mother is employed or not, mother's literacy, income and expenditure balance, monthly family income, mother's educational level) have an effect on mother's practices. Moreover, mother knowledge has some effect $(p=.03)$ on mother's responsive feeding practices. However, table 8 reveals that after controlling the socio-demographic factor there is no effect of knowledge on practices. Similar to other findings, these results indicate that socio- demographic factors have a strong influence on parents' knowledge and practices [16].

Findings on child's health and nutrition around $45 \%$ of infants received complementary liquids prior to 6 months (typically around $4-5$ months) and $12 \%$ of infants were given infant formula primarily for medical reasons. Consistently, UNICEF (2008) estimated that 40 to 50 percent of young children in developing countries are with similar negative consequences [17]. Finding on parental support for early learning found that $54 \%$ of households engaged in three or more early and school readiness activities with their child in the past three days. Story telling is the least common and reads books is most common practices among parents. The study found that around $25 \% 3$ to 5 year's old children attended kindergarten school. However, parents reported that among the kindergarten group $92 \%$ children recognized letter or number whether it was $50 \%$ for non-kindergarten children which are similar to Wallander et al. study[18].

Although the present study tried to maintain a sound methodology and analysis of data, nerveless it is not free from certain draw backs and limitations. Following may be said to be the major limitations of the study. The study was conducted on a limited number of respondents. In this study, the non-probability sampling technique was also used. In addition some situational factors (e.g., child birth order, number of siblings, etc.) were not introduced. 
Therefore, further studies considering these factors are necessary to get a better picture of this matter. Moreover, low income parents high income parent in urban and ruler can be studied combinedly.

\section{Conclusions and Recommendations}

In line with the purpose and objectives of the KAP study, this report has established a current picture of the sample population. The current KAP study examined parental knowledge, attitudes, and practices related to early childhood development in Bangladesh. Specifically, the study investigated trends in child rearing and care-giving practices related to child health and nutrition, family support for early learning, and child protection.

According to finding of this study, the overall knowledge regarding ECD among the parents was not good enough. However, parents had a good level of attitude toward child rearing issues. On the other hand, few parents practiced higher level of early learning stimulation. However, practices regarding child's responsive feeding were very low. Therefore, it suggested that there was some gap between knowledge, attitude, and practices. In addition to that, regression analysis revels that parents' socio economic status and home environment are good predictors of parental knowledge and practices. As a result, the following interventions are recommendations to translate the findings into action.

\section{Recommendation 1}

ECD knowledge should be stated at the community level. Programs should be taken to promote the importance of ECD and encourage parents to practices more activities that enhance their children's development.

\section{Recommendation 2}

The strategy should promote parents engagement with their children through makes them aware of the benefits of kindergarten, preprimary school, and the importance of play based learning.

\section{Recommendation 3}

Focus future parenting activities on improving knowledge, attitude, and practices related to the child early stimulation, in particular, cognitive benefits associated with early stimulation such as play with child read book.

Efforts to promote sustainable change related to the child early stimulation and development should include Family member

\section{Recommendation 4}

Ensure target parenting and ECD programs to reach lower income and slum people. Efforts should focus on ensuring low educative parents have access to kindergarten and interventions that focus on ECD including psychosocial stimulation.

\section{REFERENCES}

[1] Early Childhood Development (n d -c) Retrieved from https://www unicef org/dprk/ecd pdf.

[2] Evidence for ECD Investment | Early Childhood | UNICEF (n d ) Retrieved June 6, 2017, from https://www unicef org/earlychildhood/index_69851 html.

[3] WHO/Early child development (2017) WHO Retrieved from: http://wwwwhoint/maternal_child_adolescent/topics /child/development/en/.

[4] Grantham-McGregor, S , Cheung, Y B , Cueto, S , Glewwe, P , Richter, L , Strupp, B , \& International Child Development Steering Group, the I C D S (2007) Developmental potential in the first 5 years for children in developing countries Lancet (London, England), 369(9555), 60-70 http://doi org/10 1016/S0140-6736(07)60032-4.

[5] Wallander, J L , Bann, C M , Biasini, F J , Goudar, S S , Pasha, O, Chomba, E, ... Carlo, W A (2014) Development of children at risk for adverse outcomes participating in early intervention in developing countries: a randomized controlled trial Journal of Child Psychology and Psychiatry, and Allied Disciplines, 55(11), 1251-9 http://doi org/10 $1111 /$ jcpp 12247.

[6] Rao, N , Sun, J , Wong, J M S , Weekes, B , Ip, P , Shaeffer, S , ... Lee, D (2014) Early childhood development and cognitive development in developing countries: A rigorous literature review Department for International Development Retrieved from http://r4d dfid gov uk/.

[7] National Academies of Sciences, E and M (2016b) Parenting Matters (V L Gadsden, M Ford, \& H Breiner, Eds ) Washington, D C : National Academies Press http://doi org/10 17226/21868.

[8] Madden, V., Domoney, J., Aumayer, K., Sethna, V., Iles, J., Hubbard, I., ... Ramchandani, P. (2015). Intergenerational transmission of parenting: Findings from a UK longitudinal study. The European Journal of Public Health, 25(6), 1030 1035 .

[9] Manasi Kumar, Beatrice Madeghe, Judith Osok-Waudo, Grace Nduku Wambua \& Beatrice Kagai Amugune (2018). Shifting parental roles, caregiving practices and the face of child development in low resource informal settlements of Nairobi: experiences of community health workers and school teachers., Annals of General Psychiatryvolume 17, 50.

[10] Bradley RH, Corwyn RF, McAdoo H, Coll C. (2001). The home environments of children in the United States: Part I. Variations by age, ethnicity, and poverty status. Child Development, 72, 1844-1867.

[11] Coley RJ. (2002). An uneven start: Indicators of inequality 
in school readiness. Princeton, NJ: Educational Testing Service.

[12] Hart B, Risley TR. (1995). Meaningful differences in the everyday experiences of young American children. Baltimore: Brookes.

[13] Evans (2004). Journal of Applied Developmental Psychology, 28(5-6), 411-426.

[14] Studies, C (n d ) Poverty and Violence in Korail Slum in Dhaka

[15] Korail, Brac. (2014), (December), 2014. Retrieved from http://www.brac.net/sites/default/files/factsheet/new/Korail

[16] Winter L, Morawska A, Sanders MR. The effect of behavioral family intervention on knowledge of effective parenting strategies. J Child Fam Stud 2012; 21: 881-90. [http://dx.doi.org/10.1007/s10826-011-9548-y]

[17] UNICEF - The State of the World's Children 2001 (n d ) Retrieved from https://www unicef org/sowc01/references htm.

[18] Wallander et al. (2014). Dose of early intervention treatment during children's first 36 months of life is associated with developmental outcomes: An observational cohort study in three low/low-middle income countries. BMC Pediatrics 14(1), 28. 